\title{
An Early Detection of Acute Compartment Syndrome in Fastened Zip-Tie Rat Model Using Dynamic Phosphorous-31 Magnetic Resonance Spectroscopy at 9.4 Tesla
}

\section{Hiroki Ohta}

Jikei University School of Medicine: Tokyo Jikeikai Ika Daigaku

Nhat-Minh Van Vo

Tokyo Metropolitan University: Shuto Daigaku Tokyo

Junichi Hata

Jikei University School of Medicine: Tokyo Jikeikai Ika Daigaku

Koshiro Terawaki

Tokyo Metropolitan University: Shuto Daigaku Tokyo

\section{Takako Shirakawa}

Tokyo Metropolitan University: Shuto Daigaku Tokyo

Hirotaka James Okano ( $\nabla$ hjokano@jikei.ac.jp )

the Jikei University School of Medicine https://orcid.org/0000-0003-4611-7098

\section{Research}

Keywords: Acute compartment syndrome (ACS), limb salvage, non-invasive diagnosis method, phosphorous-31 magnetic resonance spectroscopy (31P-MRS), creatinine phosphokinase (CPK), pH, inorganic phosphate $(\mathrm{Pi})$, phosphocreatine $(\mathrm{PCr})$, and adenosine triphosphate (ATP)

Posted Date: January 13th, 2021

DOl: https://doi.org/10.21203/rs.3.rs-143667/v1

License: (c) (i) This work is licensed under a Creative Commons Attribution 4.0 International License. Read Full License 


\section{Abstract}

Introduction

Acute compartment syndrome (ACS) leads to a series of health problems, limb salvage, disability, and even death. In vivo phosphorus-31 magnetic resonance spectroscopy ( $\left.{ }^{31} \mathrm{P}-\mathrm{MRS}\right)$ provides a unique noninvasive method to assess skeletal muscle metabolisms such as inorganic phosphate ( $\mathrm{Pi})$, phosphocreatine (PCr), and adenosine triphosphate (ATP). The study aims to assess the ability of dynamic ${ }^{31} \mathrm{P}-\mathrm{MRS}$ in the early detection of muscular damage in ACS.

Materials \& Methods

The study induced the fastened zip-tie model of ACS on normotensive Sprague-Dawley rats $(n=6)$. The spectra were acquired in Bruker 9.4-Tesla preclinical scanner using ${ }^{1} \mathrm{H} /{ }^{31} \mathrm{P}$ surface coil. ${ }^{31} \mathrm{P}-\mathrm{MRS}$ spectra and blood samples were obtained at time 0 (pre-ischemic phase) and every 15 minutes during the compression (120 minutes) and the reperfusion phase (90 minutes). ${ }^{31} \mathrm{P}-\mathrm{MRS}$ spectra findings were compared with plasma creatine phosphokinase (CPK).

Results

$\mathrm{PCr} /(\mathrm{Pi}+\mathrm{PCr})$ ratio significantly decreased after muscle was compressed $(\mathrm{P}<0.05)$. In contrast to this, CPK did not change significantly $(P>0.05)$. Both intracellular $\mathrm{pH}$ and arterial $\mathrm{pH}$ decreased over time. However, intracellular declined significantly $(P<0.05)$ at 60 minutes of ischemic state, and at 5 minutes and 60 minutes of reperfusion, while arterial pH slightly changed. After 30 minutes of ischemic, phosphomonoesters (PME) peak was detected, which was not seen at the pre-ischemic phase. It gradually increased and reached its highest peak at 120 minutes. At reperfusion state, ${ }^{31} \mathrm{P}-\mathrm{MRS}$ spectra and $\mathrm{pH}$ did not fully recover to their pre-ischemic state, and PME peak disappeared. There was a correlation between T2-weighted images and CPK from blood tests $\left(R^{2}=0.1996, P<0.05\right)$.

Conclusions

Dynamic ${ }^{31}$ P-MRS technique is more clearly and rapidly detect the bioenergetic and mitochondrial functions change than blood test in a fastened zip-tie rat model of ACS. This technique is a promising non-invasive method to detect the early ischemic muscular damage in ACS.

\section{Introduction}

Acute compartment syndrome (ACS) of the extremities can damage the muscles, nerves, and vasculature[1, 2]. ACS occurs more frequently in disaster-prone countries[3]. The time to decompressive fasciotomy is crucial; if not treated within 6-8 hours, the limb will lose its viability, limb salvage, and the patient will be even death[4,5]. Thus, monitoring the disease progression that involves both ischemic and recovery is essential to evaluate skeletal muscle status and differentiate reversible and irreversible tissue 
damage of skeletal muscles. However, detecting the early ischemic muscular damage in ACS remains a difficult task. While there are several different diagnostic methods, including pressure levels, biomarkers, and imaging techniques, the conventional diagnosis techniques provide insufficient evidence to diagnose a patient's condition is most cases[6]. It is currently in the stage of research and development. For early diagnosis and early treatment of ACS, it is necessary to evaluate muscle bioenergetics and metabolism in vivo non-invasively[6-8].

One key parameter used in evaluating ACS signs is skeletal muscles' energy metabolism[9]. Magnetic resonance spectroscopy (MRS) provides a unique technique that allows for assessing tissue metabolic properties. Phosphorous-31 MRS ( $\left.{ }^{31} \mathrm{P}-\mathrm{MRS}\right)$ offers the ability to directly quantify essential metabolites such as inorganic phosphate $(\mathrm{Pi})$, phosphocreatine $(\mathrm{PCr})$, and adenosine triphosphate (ATP). More specifically, ${ }^{31} \mathrm{P}-\mathrm{MRS}$ can dynamically monitor high-energy phosphate depletion and re-synthesis rates during ischemic to reperfusion state. In addition, it can measure the intracellular $\mathrm{pH}$ and mitochondrial oxidative capacity. $[9,10]$ These are valuable indices used to differentiate between normal and pathological states.

While most ACS cases have been scanned at clinical Magnetic Resonance Imaging (MRI) machine, we used a pre-clinical ultra-high field (9.4 T) to gain a higher signal-to-noise ratio (SNR), shorten data acquisition time, improve spectra quality, and reduce metabolite overlapping. Therefore, the quantification of energy metabolism is more accurate.[11-13]

The use of serum biomarkers in ACS has several limitations that have not shown specificity in detecting ACS's early symptoms[7, 14, 15]. Creatinine phosphokinase (CPK), known as CK (creatinine kinase), is an enzyme present in various tissues and cell types such as skeletal muscle, myocardium, and brain. The elevated CPK level frequently occurs in heart attack, skeletal muscle injury, and exhausting exercise. According to the previous study, CPK concentrations greater than 4,000 U/L are associated ACS development in humans[16]. It has been suggested that measurement of CPK could be a potential biomarker to indicate ACS[17].

This study aims to examine whether dynamic ${ }^{31} \mathrm{P}-\mathrm{MRS}$ will provide early detection of skeletal muscle bioenergetic changes in ACS. In the present experiment, we acquired ${ }^{31} \mathrm{P}-\mathrm{MRS}$ spectra, Hydrogen Magnetic Resonance Imaging's image ( $\left.{ }^{1} \mathrm{H}-\mathrm{MRI}\right)$, and blood samples from the fastened zip-tie rat model of ACS. Comparison of ${ }^{31} \mathrm{P}-\mathrm{MRS}$ with blood test will offer essential information about muscle pathophysiology from pre-ischemic to ischemic and reperfusion phase.

\section{Materials And Methods}

\section{Animals}

Male normotensive Sprague-Dawley rats ( $\mathrm{n}=6$; 9 to 12 weeks old; $276-499 \mathrm{~g}$ ) obtained from Nihon SLC (Japan SLC, Inc. Shizuoka, Japan) were housed in individual cages in a controlled room (temperature: 24- 
$25^{\circ} \mathrm{C}$; humidity: $50-60 \%$ ) and a $12: 12$ hours light-dark cycle. The rats were allowed free access to food (CE-2, CLEA Japan, Inc., Tokyo, Japan) and water. The research protocol was approved by the Institutional Animal Care and Use Committee of The Jikei University School of Medicine (Protocol number: 2019-043C1). All experimental procedures were conducted under the Fundamental Guidelines for Proper Conduct of Animal Experiments and Related Activities in Academic Research Institutions issued by the Japanese Ministry of Education, Culture, Sports, Science and Technology [18].

\section{The fastened zip-tie rat model of ACS procedure}

A vascular surgeon performed the fastened zip-tie rat model of ACS. Anesthesia was induced using $3 \%$ isoflurane kept within the laboratory "Small Animal Anesthesia System" (SBN-487, Shinano, Tokyo, Japan) and titrated to maintain an acceptable standard during the experiment. This isoflurane concentration is commonly used for MR procedures without impacting the results obtained. Respiratory was monitored in real-time using a Magnetic Resonance (MR)-compatible Small Animal Monitoring \& Getting System (SA Instruments, Inc.,10, NY, USA). First, the rats were placed on a heating pad in a supine position and shifted into a lateral position. Then, two plastic zip-ties (ELPA, Osaka, Japan; length: $150 \mathrm{~mm}$, width: $3.6 \mathrm{~mm}$ ) were held with three fixed positions on the rat's inguinal region ( 3 fixed points were sewn directly around the inguinal region avoiding vascular damages) (fig.1). After the pre-ischemic scanning, the ischemic was induced by fastening two zip ties. Pre-ischemic and ischemic states were monitored continuously from time zero to 120 minutes. After releasing the zip-ties, the reperfusion state was followed for 90 minutes.

\section{Experimental setup}

After preparation for the fastened zip-tie rat model of ACS, the rats were placed on a supine position and immobilized on the MR cradle with the hindlimb in the full-extended position. The MR cradle is connected to a small animal ventilator (SA Instruments, Inc., 10, NY, USA). MR coils were positioned on the hindlimb's lateral side and firmly secured with tape at pre-ischemic state. Ischemic was then induced by fastening the zip tie. After 120 minutes of ischemic, perfusion was resumed immediately by cutting the zip tie. ${ }^{31} \mathrm{P}-\mathrm{MRS}$ spectra were acquired at rest, during muscle was compressed (120 minutes) and reperfusion (90 minutes). During the MR procedure, the concentration of $\mathrm{pH}$ and $\mathrm{CPK}$ were analyzed by blood samples obtained from the tail artery. The rat's respiration rate was continuously monitored (SA Instruments, Stony Brook, NY, USA) and controlled 80 to 120/minutes throughout the MR scanning. Body temperature was maintained at about 37 degrees by heating bath circulator equipment (CW-05G, lab companion, Daejeon, Korea) connected to the MR cradle. All the experiment's items are demonstrated in fig. 2

\section{${ }^{1} \mathrm{H}-\mathrm{MRI}$ and ${ }^{31} \mathrm{P}-\mathrm{MRS}$ acquisition}

The measurements were performed on a preclinical MR scanner biospec 9.4 Tesla (Bruker Optik GmbH, Ettlingen, Germany) and controlled by the paravision 6.2 software package (Bruker Biospin). The rats' knee and leg were fully extended, and a Bruker dual resonance linearly polarized coils ${ }^{1} \mathrm{H} /{ }^{31} \mathrm{P}\left({ }^{1} \mathrm{H}\right.$ : 
400.525 MHz \& ${ }^{31} \mathrm{P}: 162.056 \mathrm{MHz}$ ) with $20 \mathrm{~mm}$ inner diameter was attached underneath the hind limb to perform shimming, and the knee was centered over the surface coil. The leg was secured to the ${ }^{1} \mathrm{H} /{ }^{31} \mathrm{P}$ dual coil covered by masking tape to avoid potential motion during the experiment.

Localizer ${ }^{1} \mathrm{H}$-images were acquired to detect the leg's position within the sensitive area of the ${ }^{1} \mathrm{H} /{ }^{31} \mathrm{P}$ dual coil. Subsequently, the wobble adjustment was performed that allows the radiofrequency (RF) coil (measuring its absorption spectra) for manual tuning/ matching. We selected two coils (elements ${ }^{1} \mathrm{H}$ and ${ }^{31} \mathrm{P}$, respectively) with an isotropic voxel of $48 \times 48 \times 48 \mathrm{~mm}^{3}$ in the surface coil's sensitive field. The wobble curve was tuned and matched until the dip reaches the center, and its minimum is close to the zero line. After that, the BO map, used to measure a field map of the object used in a study to calculate shims, was set up. The shim was calculated based on a previously measured B0-field map to optimize the field homogeneity within the Shim volume. As a result, a proton linewidth of $120-140 \mathrm{~Hz}$ was obtained. When the line width at half height of the proton signal was about $0.5 \mathrm{ppm}$ for one free induction decay (FID), the magnetic field homogeneity was accepted. Then, the spectrometer was turned to ${ }^{31} \mathrm{P}$ nuclei. The entire procedure took about five minutes on average.

${ }^{31} \mathrm{P}$ spectra were acquired, followed by T2-weighted images, leading to a total acquisition time of 10 minutes at pre-ischemic. The interleaved ${ }^{31} \mathrm{P}-\mathrm{MRS}$, T2-weighted images, and blood samples were acquired on the hindlimb of rats from pre-ischemic to ischemic and followed by reperfusion phase. The ${ }^{31}$ P-MRS dynamic protocol consisted of $15 \mathrm{~min}$ for pre-ischemic, $120 \mathrm{~min}$ for ischemic, and $90 \mathrm{~min}$ for recovery phase, respectively, to quantify phosphate metabolite changes. Each acquisition of ${ }^{31} \mathrm{P}-\mathrm{MRS}$ (a non-localized spectra with a single pulse) was acquired with parameters: flip angle $=90^{\circ}$; repetition time $(T R)=2000 \mathrm{~ms} ;$ Averages $=192$. Total acquisition time was 6 minutes, 24 seconds. The parameters used for axial slice T2-weighted images (fig.4) as follows: "fast spin-echo sequence"; TR = $2000 \mathrm{~ms}$; time to echo $(T E)=30.69$; Refocusing angle $=143.7^{0} ;$ Rare factor $=8$; Averages $=3$, matrix $=256 \times 256$ pixels; Field of view $=35 \times 50 \mathrm{~mm}^{2} ;$ Slice thickness $=1.00 \mathrm{~mm}$, Slices $=18$; Scanning time $=3$ minutes 12 seconds). The experimental procedure workflow is illustrated in fig.3.

\section{Blood sampling procedure}

Blood samples were collected for ex vivo analysis. The 22-gauge catheter for invasive blood sampling collection was inserted into the ventral tail artery. After sampling arterial blood at the pre-ischemic state, the heparinized physiological saline was flushed into the catheter. The catheter was kept until the end of the experiment. Each amount of blood sample $(0.25 \mathrm{~mL})$ was obtained and filled into the i-STAT CG4 + cartridge (Abbott product, USA) and FUJI DRI-CHEM slide (Fujifilm Medical, Tokyo, Japan) blood test kit. Blood samples were obtained at pre-ischemic, ischemic (60 minutes \& 120 minutes), and after pressure removal (5 minutes, 60 minutes \& 90 minutes). It was assessed at each time point for measurement of inflammatory biomarker CPK. After the needle was withdrawn, we applied gentle pressure with a cotton ball to the puncture site until the bleeding stopped. 


\section{Data Processing, Statistical Analysis}

\section{Data processing}

The MRS data were first processed with TopSpin 4.0.7 software (Bruker Biospin Corp., Billerica MA). The resulting datasets were fitted in the time domain using AMARES (Advanced Method for Accurate, Robust, and Efficient Spectral Fitting) algorithm implemented in jMRUI software. The NMRSCOPE tool (jMRUI software package) created a basic set of five metabolites spectra that include Pi, PCr, and ATP. PCr and Pi peaks were fitted to Lorentzian line shapes, whereas $\mu$-ATP, a-ATP, and $\beta$-ATP signals were fitted to Gaussian line shapes.[19] PCr was used as an internal reference for calculating the absolute concentration of $\mathrm{Pi}$ and ATP[20, 21]. The PCr/(Pi+PCr) ratio, a marker of energy state's level, was calculated from $\mathrm{Pi}$ and $\mathrm{PCr}$ areas[10]. The intracellular $\mathrm{pH}$ was calculated from the chemical shift of $\mathrm{Pi}$ relative to PCr utilizing the following equation [22]

$\mathrm{pH}=6.75+\log (\delta-3.27 /(5.69-\delta)$,

Where $\delta$ is the chemical shift of the Pi peak in parts per million relatives to PCr.

T2-weighted images were analyzed using ImageJ software (Rasband, W.S., ImageJ, U. S. National Institutes of Health, Bethesda, Maryland, USA)[23]. In order to quantitively analyze the signal intensity changes, the signal intensity was measured in two compartments that correspond to the tibialis anterior and the gastrocnemius muscles (locations were indicated in fig.8). The signal intensities of these two regions of interest $(\mathrm{ROI})$ were calculated as the mean values of all pixels within the ROI. The tibia bone's signal intensity was then used as the reference value to normalize the signal intensity. The signal intensity through each different phase from the pre-ischemic phase to the recovery phase was quantified.

Blood samples analysis: Blood samples were analyzed using an automatic biochemical analyzer (FUJI DRI-CHEM 3500v, Fujifilm Medical, Tokyo, Japan) and handheld blood analyzer i-STAT 1 (Abbott product, USA). Results were obtained after 2 minutes. The analysis included $\mathrm{pH}$ and CPK [16, 24]. We set all the results over $2000 \mathrm{U} / \mathrm{L}$ to $2000 \mathrm{U} / \mathrm{L}$.

\section{Statistical analysis}

Results are presented as mean \pm SD. A repeated-measures nonparametric Friedman test was used to compare ${ }^{31} \mathrm{P}-\mathrm{MRS}$ and CPK between time points. Potential relationships between T2-weighted and CPK were assessed using Pearson's correlation analysis or the nonparametric Spearman rank-order correlation. Statistical significance was accepted at $P<0.05$. Statistical analyses performed using GraphPad Prism (version 8.0.2, GraphPad Software, Inc.)

\section{Results}

The model successfully induced ACS on rat's hindlimb compartments by using the fastened zip-tie. technique. ${ }^{31}$ P-MRS detected significant changes in muscles at all the time points (fig.5). Energy 
metabolism, signal intensities, and $\mathrm{pH}$ at rest: the metabolite concentration such as $\mathrm{PCr}, \mathrm{Pi}$, and ATP were observed as a baseline value. Typical T2-weighted fast spin-echo images were shown in fig.8.

Energy metabolism, signal intensities, and pH during muscle compression and reperfusion: After muscle compression, $\mathrm{PCr} /(\mathrm{Pi}+\mathrm{PCr}$ ) ratio immediately decreased compare to pre-ischemic level, which was 0.858 \pm 0.100 (mean $\pm \mathrm{SD}, \mathrm{n}=6$ ) (fig.6, tab.1). After 60 and 120 minutes of ischemic state, $\mathrm{PCr} /(\mathrm{Pi}+\mathrm{PCr}$ ) ratio was $0.182 \pm 0.062$ and $0.036 \pm 0.012$, respectively. Friedman test revealed a significant difference in $\mathrm{PCr} /(\mathrm{Pi}+\mathrm{PCr})$ ratio among pre-ischemic, 60 minutes, and 120 minutes of ischemic state $(\mathrm{P}<0.05$, fig.6). Intracellular $\mathrm{pH}$ significantly changed due to time $(\mathrm{P}<0.05$, fig.7, tab.2). It decreased gradually from 7.092 \pm 0.013 to $6.430 \pm 0.121$ after 120 minutes of ischemic. At thirty minutes of ischemic state, PME (phosphomonoester) peak was detected, which was not seen in the pre-ischemic phase, in the region of about from $4.7 \mathrm{ppm}$ to $5.0 \mathrm{ppm}$ to the left of the Pi peak (fig.5). SI of TA and GA muscles gradually increased in the T2-weighted images.

Once the zip-ties were released, ${ }^{31}$ P-MRS spectra instantly started to recover to the pre-ischemic level. Nevertheless, $\mathrm{PCr} /(\mathrm{Pi}+\mathrm{PCr})$ ratio did not ultimately return to normal values. At 90 minutes of reperfusion state, the corrected ratios of $\mathrm{PCr} /(\mathrm{Pi}+\mathrm{PCr})$ was $0.676 \pm 0.199$, of those in the pre-ischemic state (tab.1). The intracellular $\mathrm{pH}$ started to re-increase during the reperfusion time (tab.2). It did not fully recover to the baseline level at 90 minutes of reperfusion state $(6.533 \pm 0.492)$. PME peak gradually decreased and disappeared during reperfusion state (fig.5)

Table $1 \mathrm{PCr} /(\mathrm{Pi}+\mathrm{PCr})$ ratio and creatine phosphokinase level at different time points

\begin{tabular}{|c|c|c|c|c|c|c|}
\hline & Pre-ischemic & Ischemic & & Repefusion & & \\
\hline Minute & 0 & 60 & 120 & 125 & 185 & 215 \\
\hline \multicolumn{7}{|c|}{$\mathrm{PCr} /(\mathrm{Pi}+\mathrm{PCr})$} \\
\hline Case 1 & 0.851966 & 0.150054 & 0.023529 & 0.294941 & 0.457083 & 0.462246 \\
\hline Case 2 & 0.909465 & 0.233196 & 0.028250 & 0.284537 & 0.477218 & 0.413315 \\
\hline Case 3 & 0.894012 & 0.240060 & 0.049823 & 0.589019 & 0.795536 & 0.843511 \\
\hline Case 4 & 0.660095 & 0.074773 & 0.051328 & 0.368579 & 0.850327 & 0.874208 \\
\hline Case 5 & 0.903885 & 0.204006 & 0.031546 & 0.300803 & 0.809820 & 0.799276 \\
\hline \multirow[t]{2}{*}{ Case 6} & 0.927013 & 0.187813 & 0.029096 & 0.464188 & 0.665061 & 0.662470 \\
\hline & $0.37 \pm 0.29$ & $0.39 \pm 0.29$ & $0.56 \pm 0.34$ & $0.48 \pm 0.37$ & $0.50 \pm 0.37$ & $0.48 \pm 0.33$ \\
\hline \multicolumn{7}{|c|}{ Creatine phosphokinase level } \\
\hline Case 1 & 71 & 147 & 334 & 819 & 2222 & 2222 \\
\hline Case 2 & 61 & 102 & 245 & 205 & 1309 & 2222 \\
\hline Case 3 & 65 & 300 & 313 & 381 & 1289 & 1337 \\
\hline Case 4 & 91 & 419 & 91 & 216 & 749 & 919 \\
\hline Case 5 & 87 & 261 & 119 & 539 & 1349 & 2222 \\
\hline Case 6 & 141 & 220 & 88 & 319 & 638 & 1141 \\
\hline
\end{tabular}

Mean $\pm \mathrm{SD}(\mathrm{n}=6)$. The unit of $\mathrm{PCr}(\mathrm{Pi}+\mathrm{PCr})$ and creatine phosphokinase level are ratio and $\mathrm{U} / \mathrm{L}$ , repectively. 
Table 2 Intracellular $\mathrm{pH}\left({ }^{31} \mathrm{P}-\mathrm{MRS}\right)$ and $\mathrm{pH}$ (arterial blood) at different time points

\begin{tabular}{|c|c|c|c|c|c|c|}
\hline & Pre-ischemic & Ischemic & & Repefusion & & \\
\hline Minute & 0 & 60 & 120 & 125 & 185 & 215 \\
\hline \multicolumn{7}{|c|}{ pH ( $\left.{ }^{31} \mathrm{P}-\mathrm{MRS}\right)$} \\
\hline Case 1 & 7.11 & 6.85 & 6.47 & 6.39 & 6.54 & 6.53 \\
\hline Case 2 & 7.08 & 6.84 & 6.41 & 6.35 & 6.44 & 6.57 \\
\hline Case 3 & 7.10 & 6.85 & 6.55 & 6.54 & 7.02 & 7.06 \\
\hline Case 4 & 7.08 & 6.52 & 6.20 & 6.23 & 6.09 & 6.13 \\
\hline Case 5 & 7.08 & 6.83 & 6.46 & 6.37 & 5.84 & 5.84 \\
\hline \multirow[t]{2}{*}{ Case 6} & 7.10 & 6.88 & 6.49 & 6.49 & 7.05 & 7.07 \\
\hline & $7.092 \pm 0.013$ & $6.795 \pm 0.136$ & $6.430 \pm 0.126$ & $6.395 \pm 0.100$ & $6.497 \pm 0.484$ & $6.533 \pm 0.494$ \\
\hline \multicolumn{7}{|c|}{$\mathrm{pH}$ (arterial blood) } \\
\hline Case 1 & 7.50 & 7.38 & 7.35 & 7.35 & 7.36 & 7.36 \\
\hline Case 2 & 7.45 & 7.44 & 7.40 & 7.38 & 7.39 & 7.39 \\
\hline Case 3 & 7.47 & 7.42 & 7.39 & 7.38 & 7.41 & 7.39 \\
\hline Case 4 & 7.50 & 7.43 & 7.45 & 7.45 & 7.48 & 7.46 \\
\hline Case 5 & 7.43 & 7.38 & 7.35 & 7.36 & 7.38 & 7.38 \\
\hline \multirow[t]{2}{*}{ Case 6} & 7.46 & 7.36 & 7.38 & 7.37 & 7.36 & 7.36 \\
\hline & $7.470 \pm 0.030$ & $7.415 \pm 0.027$ & $7.393 \pm 0.038$ & $7.387 \pm 0.035$ & $7.399 \pm 0.044$ & $7.395 \pm 0.035$ \\
\hline
\end{tabular}

Mean \pm SD $(n=6)$

After release, muscles' SI became inhomogeneous, especially the SI of TA and GA muscles wherein they are remarkably higher than those of other areas (fig.8). At 90 minutes of reperfusion state, the high SI of TA and GA muscles were found to be preserved. The SI of the two regions were obtained as relative values to the mean baseline signal. The results were $816.300 \pm 343.785 \%$ (TA muscle), $700.267 \pm$ 185.913 (GA muscle) (tab.3) 
Table 3 The signal intensity values of TA and GA muscles

\begin{tabular}{|c|c|c|c|c|c|c|}
\hline & Pre-ischemic & Ischemic & & Repefusion & & \\
\hline Minute & 0 & 60 & 120 & 125 & 185 & 215 \\
\hline \multicolumn{7}{|c|}{ Signal intensity (Anterior tibialis muscle) } \\
\hline Case 1 & 14.58371 & 76.99370 & 88.91886 & 119.68070 & 148.83080 & 127.74970 \\
\hline Case 2 & 13.87853 & 75.03086 & 84.21032 & 71.18124 & 74.22397 & 68.17241 \\
\hline Case 3 & 10.58305 & 72.19746 & 77.73060 & 82.73040 & 76.57127 & 80.05679 \\
\hline Case 4 & 11.60603 & 83.03710 & 88.80301 & 108.34590 & 108.28930 & 92.60437 \\
\hline Case 5 & 18.08427 & 76.87059 & 70.70295 & 103.81530 & 66.77621 & 79.96409 \\
\hline \multirow[t]{2}{*}{ Case 6} & 12.35590 & 84.52028 & 96.28907 & 86.58480 & 109.17940 & 103.52800 \\
\hline & $13.515 \pm 2.673$ & $78.108 \pm 4.745$ & $84.442 \pm 9.091$ & $95.390 \pm 18.181$ & $97.312 \pm 31.020$ & $92.013 \pm 21.291$ \\
\hline \multicolumn{7}{|c|}{ Signal intensity (Gastrocnemius muscle) } \\
\hline Case 1 & 6.080752 & 130.8507 & 153.3366 & 238.4836 & 213.378 & 151.922 \\
\hline Case 2 & 11.78455 & 77.81928 & 86.8085 & 88.18499 & 67.86772 & 64.28829 \\
\hline Case 3 & 8.052729 & 87.19415 & 85.92879 & 103.5566 & 135.0759 & 141.1561 \\
\hline Case 4 & 10.98872 & 70.50391 & 94.74831 & 97.95076 & 109.4305 & 92.67996 \\
\hline Case 5 & 16.43105 & 78.55369 & 74.08718 & 103.5006 & 68.74231 & 78.23589 \\
\hline \multirow[t]{2}{*}{ Case 6} & 8.215281 & 74.15139 & 80.41153 & 77.50794 & 116.4496 & 102.2937 \\
\hline & $10.259 \pm 3.673$ & $86.512 \pm 22.425$ & $95.887 \pm 28.976$ & $118.197 \pm 59.775$ & $118.491 \pm 53.670$ & $105.096 \pm 34.761$ \\
\hline
\end{tabular}

\section{Mean $\pm \mathrm{SD}(\mathrm{n}=6)$}

Blood sample results from pre-ischemic to reperfusion state: No significant changes were seen in CPK concentration during the ischemic state that compared to the pre-ischemic level $(P>0.05$, fig.6). At ischemic state, CPK concentration changed from $241.500 \pm 113.280 \mathrm{U} / \mathrm{L}$ to $198.333 \pm 112.889$ at 60 minutes and 120 minutes, respectively (tab.1). It slightly changed compare to the pre-ischemic level ( $86 \pm$ 29.469). CPK gradually increased throughout the experiment period. At 90 minutes of reperfusion, CPK raised more rapidly $(1566.167 \pm 493.304 \mathrm{U} / \mathrm{L})$. The arterial blood pH level slightly changed from preischemic $(7.470 \pm 0.030)$ to 60 minutes of ischemic $(7.415 \pm 0.027)$. At 120 of ischemic, it significantly changed $(7.393 \pm 0.038)$. At 90 minutes of reperfusion, it not fully returned to pre-ischemic value (fig.7, tab.2). There was a significant correlation of T2-weighted image with CPK concentration from blood examination $\left(R^{2}=0.1996, P<0.05\right)$.

\section{Discussion}

In this study, the goal was accepted as ${ }^{31}$ P-MRS provided a reliable, sensitive measure of muscle metabolites changes in this fastened zip-tie rat model of ACS. This study is the first finding in the world expected to lead to limb salvage with ACS patients. These data are consistent with previous data from the arterial occlusion model [25]. The ${ }^{31} \mathrm{P}-\mathrm{MRS}$ spectra showed a predictable change to a constant level when plastic zip ties were fastened, suggesting a loss of perfusion to the tissues. ${ }^{31} \mathrm{P}$-MRS spectra data confirms that the fastened zip-tie rat model of ACS significantly reduced the blood flow into the compartment's tissues. It is significant to note that ${ }^{31} \mathrm{P}-\mathrm{MRS}$ spectra changes occur immediately after 
decreased perfusion demonstrating real-time responsiveness. These data showed that from 60 to 120 minutes of ischemic state, the ratio of $\mathrm{PCr} /(\mathrm{Pi}+\mathrm{PCr})$ was firmly lower than the baseline value. In contrast to this, the CPK concentration slightly changed compared to the ischemic state concentration[7]. It could be suggested that ${ }^{31} \mathrm{P}-\mathrm{MRS}$ values detect more rapidly and sensitively bio-energetics' change status in muscles than CPK. ${ }^{31} \mathrm{P}-\mathrm{MRS}$ is able to detect early muscle damage signs of ACS non-invasively. This observation is essential to differentiate between invasive measures such as intra-compartmental pressures and non-invasive measures such as ${ }^{31} \mathrm{P}$-MRS. Additionally, during the ischemic phase and recovery phase, we also found the PME peak was considered to be delivered mainly from some kinds of phospholipids. It is an additional sign that helps in detecting early muscle damage of ACS.[26]

The edema of hindlimb's compartment depending on the location in the muscles were determined by ${ }^{1} \mathrm{H}-$ MR images. The SI gradually increased during the ischemic phase and overshoots immediately after release the muscle compression as shown in T2-weighted images (Fig. 7). During the recovery process, the elevated SI of T2-weighted images showed that the relationship with the water content increased in the extracellular space phenomenon[27]. After the release of muscle compression, it is understood that which is thought to be caused by increased vascular permeability in skeletal muscle induced by oxygenderived free radicals, apparent edema around the skeletal muscle occurs. These findings suggest that alterations in skeletal muscle high-energy phosphate metabolism occur early in the pathophysiology of ACS.

In most cases of the reperfusion state, the CPK concentration showed over $2000 \mathrm{U} / \mathrm{L}$. The blood analyzer equipment could not display the specific value of CPK concentration, which ere exceeded the upper limit of measurement (2000 U/L). However, it was considered that detailed numerical measurement was unnecessary because it was sufficiently high compared to the pre-ischemic level. The CPK concentrations significantly increased over pre-ischemic at 90 minutes of reperfusion state. However, it was not significantly increased and unstable over the pre-ischemic level at 60 minutes after zip-ties fastened. The current data revealed the difference in the timing of CPK and ${ }^{31} \mathrm{P}-\mathrm{MRS}$ metabolites concentration during the ischemic state. It proved that the increase in CPK concentration observed was not immediately, and so, CPK is not suitable to detect the early ischemic muscular damage in ACS. However, CPK can be used as a useful biomarker to indicate the extent of muscle damage in the sub-acute phase.[28] Moreover, CPK has been used as a primary biomarker in recognizing trauma for patients with ACS.[16] In addition, a correlation between T2-weighted images signal intensity (Tibialis anterior \& Gastrocnemius muscles regions) and CPK has been found. Once the zip-ties were released, the phenomenon of blood reperfusion injury is more natural to occur with the tissue swelling, fluid inflow, and compartment compression. This result found demonstrated the muscle damage was consistent for edema symptoms.

The fastened zip-tie rat model is a simple model to research crush injuries as encountered seen in a time of accidents or disasters. It can be useful to evaluate the systematic effects of releasing pressure from trapped or crush extremities. This model showed an advanced method of pressure creation compared to the previous study.[28-30] In our study, there was a difference between the control pH of ${ }^{31} \mathrm{P}-\mathrm{MRS}$ and 
the blood test. Especially at the ischemic state, ischemic tissue $\mathrm{pH}$ (6.5) from ${ }^{31} \mathrm{P}-\mathrm{MRS}$ spectra was lower than arterial $\mathrm{pH}$ (7.4) from blood tests. The value of $\mathrm{pH}$ decreased more extensively in ischemic tissue than in circulation blood. Anaerobic glycolysis lowered the $\mathrm{pH}$ in the ischemic area. However, homeostasis controlled systematic $\mathrm{pH}$ value tightly, and the value was almost unchanged (Normal mammals blood $\mathrm{pH}=7.40 \pm 0.02$ ). According to the previous study, there was a difference between the arterial blood $\mathrm{pH}$ and the superficial $\mathrm{pH}$ value.[31]

The present study has several limitations. Firstly, we were only able to use the surface coil to examine the rats' legs. The surface coil sensitivity area was limited; therefore, the SNR was not as good as we expected, even though it provided precise ${ }^{31} \mathrm{P}-\mathrm{MRS}$ results. As a result, we only measured the signal intensity of the two types of muscles. However, it is enough to prove the evidence of edema appeared in the ACS model.[25]

Secondly, the requirement for several groups with multiple animals was outside the experimental range of this study. Certainly, comparing ${ }^{31} \mathrm{P}-\mathrm{MRS}$ and blood samples in ACS from multiple groups with longer ischemic time and treating the injury hindlimb with medicine is the next step for this line of research. There is also tremendous research in the field of regenerative medicine, with possible application in emergency medicine. It has been reported that the clinical efficacy of mesenchymal stem cell therapy for ischemic diseases[32]. Therefore, mesenchymal stem cell therapy has the potential for ACS. By advancing this research, we hope that the survival of patients rescued from disasters will be improved and that the deterioration of quality of life due to unnecessary amputation of the lower limbs will be prevented.

\section{Conclusion}

Our study showed the possibility of a non-invasive, reliable, and sensitive assessment of muscle metabolites change with ${ }^{31} \mathrm{P}-\mathrm{MRS}$. Especially, acquiring the data of ${ }^{31} \mathrm{P}-\mathrm{MRS}$ with MRI ultra-field $9.4 \mathrm{~T}$ benefits from increased SNR and spectra quality. The research demonstrated that dynamic ${ }^{31} \mathrm{P}-\mathrm{MRS}$ measurements are faster and more accurate than blood sampling test. Dynamic ${ }^{31} \mathrm{P}-\mathrm{MRS}$ can be useful for real-time detecting the early ischemic muscular damage in ACS.

\section{Abbreviations}

ACS: Acute compartment syndrome; $\mathrm{B}_{0}$ : External magnetic field; SE: Spin echo; SI: signal intensity; TR: Time repetition; TE: Echo time; MRI: Magnetic resonance imaging; ${ }^{31} \mathrm{P}-\mathrm{MRS}$ : ${ }^{31} \mathrm{Phosphorus} \mathrm{magnetic}$ resonance spectroscopy; TA: Tibialis anterior; GA: Gastrocnemius; PCr: Phosphocreatine; Pi: Inorganic phosphate; ATP: Adenosine triphosphate; SNR: Signal to noise ratio; CK: Creatine kinase; CPK: Creatine phosphokinase; PME: Phospho-monoester.

\section{Declarations}


Acknowledgements

The authors would like to thank all the staffs: Yasuo Kimura, Hazuki Sato, Tamae Ouchi (Laboratory Animal Facilities, The Jikei University School of Medicine), Asakura Tadashi (Radioisotope Research Facilities) for their active involvement in taking care of the rats and equipment's' preparation during this study.

\section{Authors' contribution}

H.O., N-M.V.V. wrote the main manuscript. H.O designed the experiments. N-M.V.V., K.T., and J.H. performed the MRI scanning and data analysis. H.J.O., and T.S. helped conduct the literature review and manuscript amendment. All authors reviewed the manuscript.

\section{Funding}

This work was supported by JSPS KAKENHI Grant Number JP18K16404 (to Hiroki Ohta)

\section{Availability of supporting data}

Data are not collected from a public database. All relevant data are available upon request from the corresponding author.

\section{Ethics approval}

This study was approved by the Institutional Animal Care and Use Committee of The Jikei University School of Medicine (Protocol number: 2019-043C1). All experimental procedures were conducted under the Fundamental Guidelines for Proper Conduct of Animal Experiments and Related Activities in Academic Research Institutions issued by the Japanese Ministry of Education, Culture, Sports, Science and Technology.

\section{Consent for publication}

Not applicable

\section{Competing interests}

The authors declare that they have no competing interests.

\section{Author details}

${ }^{1}$ Divison of Regenerative Medicine, Research Center for Medical Sciences, The Jikei University School of Medicine. ${ }^{2}$ Department of Radiological Sciences, Tokyo Metropolitan University.

\section{References}


1. Köstler, W., P.C. Strohm, and N.P. Südkamp, Acute compartment syndrome of the limb. Injury, 2004. 35(12): p. 1221-7.

2. Cone, J. and K. Inaba, Lower extremity compartment syndrome. Trauma Surg Acute Care Open, 2017. 2(1): p. e000094.

3. MacKenzie, J.S., et al., A review of the epidemiology and treatment of orthopaedic injuries after earthquakes in developing countries. World journal of emergency surgery : WJES, 2017. 12: p. 9-9.

4. Pechar, J. and M.M. Lyons, Acute Compartment Syndrome of the Lower Leg: A Review. J Nurse Pract, 2016. 12(4): p. 265-270.

5. Galyfos, G., et al., Acute Compartment Syndrome of the Lower Extremity: Update on Proper Evaluation and Management. Journal of Vascular and Endovascular Surgery, 2016. 01.

6. McMillan, T.E., et al., Diagnosing acute compartment syndrome-where have we got to? Int Orthop, 2019. 43(11): p. 2429-2435.

7. Shadgan, B., et al., Diagnostic techniques in acute compartment syndrome of the leg. J Orthop Trauma, 2008. 22(8): p. 581-7.

8. Shah, P.K., et al., In vivo (31)P NMR spectroscopy assessment of skeletal muscle bioenergetics after spinal cord contusion in rats. Eur J Appl Physiol, 2014. 114(4): p. 847-58.

9. Miki, N., et al., Effects of denervation on energy metabolism of rat hindlimb muscles: application of 31P-MRS and 19F-MRS. Journal of Orthopaedic Science, 1999. 4(5): p. 370-375.

10. Yoshida, N., et al., Evaluation of disuse atrophy of rat skeletal muscle based on muscle energy metabolism assessed by 31P-MRS. Journal of physiological anthropology and applied human science, 2001. 20(4): p. 247-252.

11. Bakermans, A.J., et al., In vivo mouse myocardial (31)P MRS using three-dimensional image-selected in vivo spectroscopy (3D ISIS): technical considerations and biochemical validations. NMR Biomed, 2015. 28(10): p. 1218-27.

12. Qiao, $\mathrm{H}$., et al., In vivo 31P MRS of human brain at high/ultrahigh fields: a quantitative comparison of NMR detection sensitivity and spectral resolution between 4 T and 7 T. Magn Reson Imaging, 2006. 24(10): p. 1281-6.

13. Lu, M., W. Chen, and X.-H. Zhu, Field dependence study of in vivo brain (31) P MRS up to 16.4 T. NMR in biomedicine, 2014. 27(9): p. 1135-1141.

14. Brancaccio, P., G. Lippi, and N. Maffulli, Biochemical markers of muscular damage. Clin Chem Lab Med, 2010. 48(6): p. 757-67.

15. Vrouenraets, B.C., et al., Value of laboratory tests in monitoring acute regional toxicity after isolated limb perfusion. Ann Surg Oncol, 1997. 4(1): p. 88-94.

16. Valdez, C., et al., Serum creatine kinase levels are associated with extremity compartment syndrome. J Trauma Acute Care Surg, 2013. 74(2): p. 441-5; discussion 445-7.

17. Singh, A., et al. Serum Creatine Kinase: A Predictive Biomarker for Diagnosis of Acute Compartment Syndrome in the Paediatric Population. 2018. 
18. Ohta, H., et al., Pitfalls of invasive blood pressure monitoring using the caudal ventral artery in rats. Sci Rep, 2017. 7: p. 41907.

19. Jablonski, M., J. Starcukova, and Z. Starcuk, Jr., Processing tracking in jMRUI software for magnetic resonance spectra quantitation reproducibility assurance. BMC Bioinformatics, 2017. 18(1): p. 56.

20. Buchli, R., et al., Assessment of absolute metabolite concentrations in human tissue by 31P MRS in vivo. Part II: Muscle, liver, kidney. Magnetic Resonance in Medicine, 1994. 32(4): p. 453-458.

21. Kemp, G.J., M. Meyerspeer, and E. Moser, Absolute quantification of phosphorus metabolite concentrations in human muscle in vivo by 31P MRS: a quantitative review. NMR Biomed, 2007. 20(6): p. 555-65.

22. Greiner, A., et al., High-energy phosphate metabolism during incremental calf exercise in patients with unilaterally symptomatic peripheral arterial disease measured by phosphor 31 magnetic resonance spectroscopy. J Vasc Surg, 2006. 43(5): p. 978-86.

23. Hata, J., [3. Introduction to MRI Image Analysis Using ImageJ]. Nihon Hoshasen Gijutsu Gakkai Zasshi, 2019. 75(1): p. 89-94.

24. Baird, M.F., et al., Creatine-kinase- and exercise-related muscle damage implications for muscle performance and recovery. J Nutr Metab, 2012. 2012: p. 960363.

25. Morikawa, S., C. Kido, and T. Inubushi, Observation of rat hind limb skeletal muscle during arterial occlusion and reperfusion by 31P MRS and 1H MRI. Magnetic Resonance Imaging, 1991. 9(3): p. 269-274.

26. Tzika, A.A., et al., Role of P-31 MR spectroscopy in assessing testicular torsion: Rat model. 1988, United States: Radiological Society of North America Inc.

27. Ackermann, P.W., et al., Increasing thigh pain: acute compartment syndrome! BMJ Case Reports, 2010. 2010: p. bcr1220092513.

28. Budsberg, S.C., et al., Comparison of NIRS, serum biomarkers, and muscle damage in a porcine balloon compression model of acute compartment syndrome. J Trauma Acute Care Surg, 2016. 81(5): p. 876-881.

29. Sheridan, G.W. and F.A.I. Matsen, An Animal Model of the Compartmental Syndrome. Clinical Orthopaedics and Related Research®, 1975. 113: p. 36-42.

30. Sheridan, G.W., F.A. Matsen, 3rd, and R.B. Krugmire, Jr., Further investigations on the pathophysiology of the compartmental syndrome. Clin Orthop Relat Res, 1977(123): p. 266-70.

31. Paillard, M., Direct intracellular pH measurement in rat and crab muscle. The Journal of physiology, 1972. 223(2): p. 297-319.

32. Ohta, H., X. Liu, and M. Maeda, Autologous adipose mesenchymal stem cell administration in arteriosclerosis and potential for anti-aging application: a retrospective cohort study. Stem Cell Research \& Therapy, 2020. 11(1): p. 538.

\section{Figures}



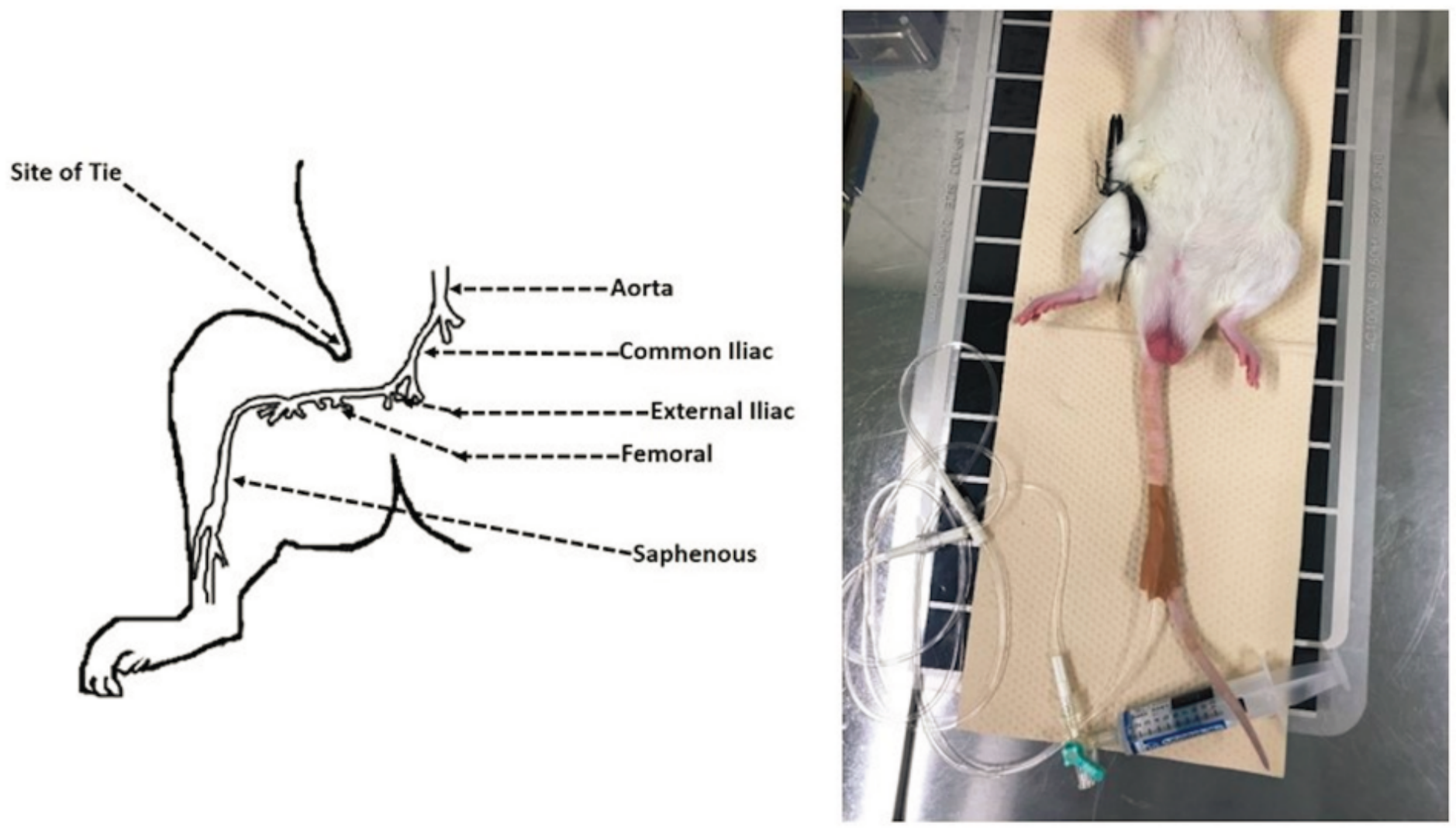

Figure 1

Fastened zip-tie rat model of ACS. Creation of an ACS model of the entire right lower limb by wrapping a zip-tie around the rat's right inguinal region. An arterial line was placed in the caudal ventral artery and set up so that blood could be sampling at any time. ACS acute compartment syndrome. 
(A)

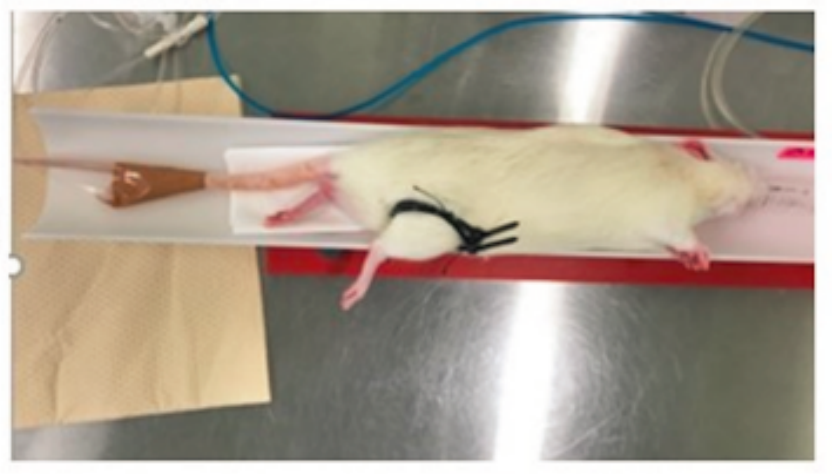

(C)

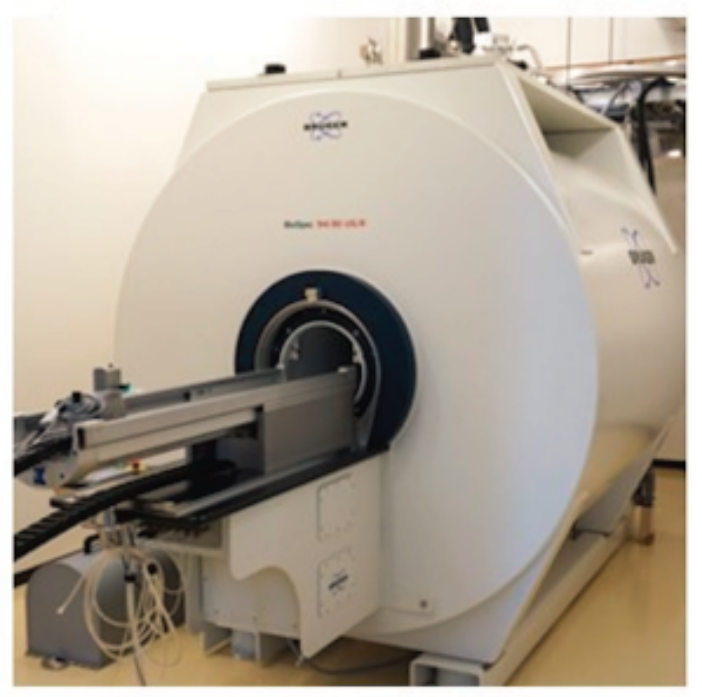

(B)

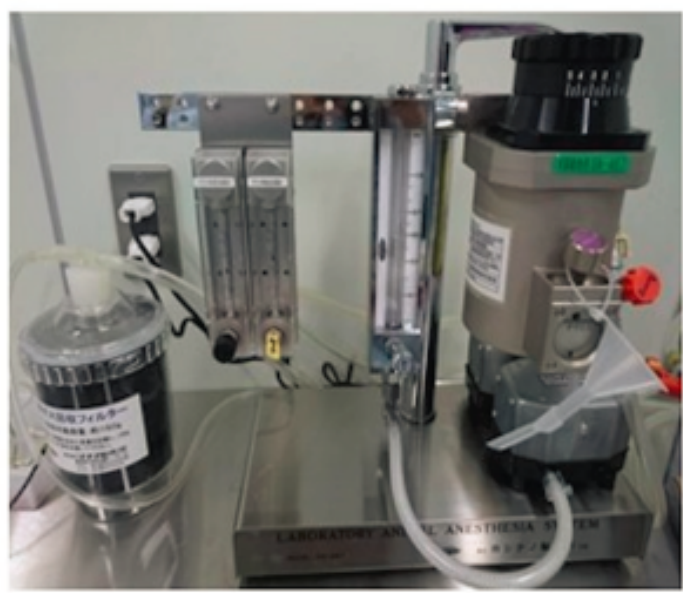

(D)

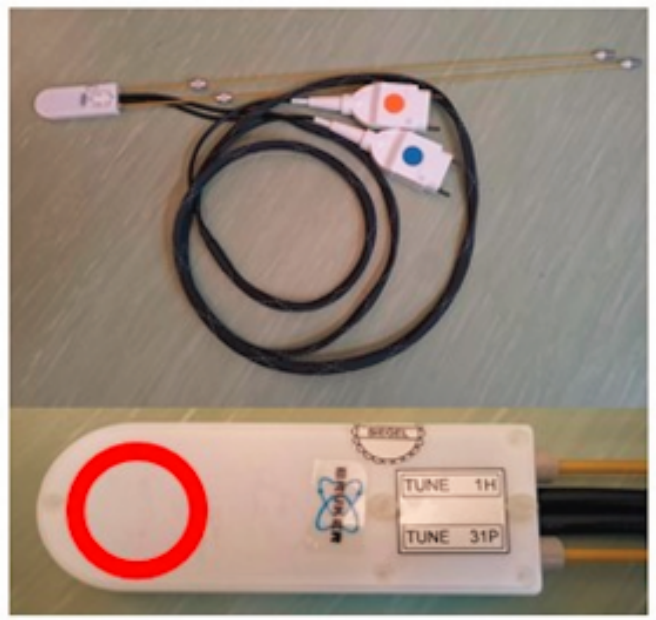

\section{Figure 2}

The experiment's equipment The prepared rat was placed in a left supine position (A) on a dedicated MR cradle and connected to an anesthesia system (B), where the inhalation concentration could be adjusted accordingly. An ultra-high field 9.4 Tesla MRI machine (C) and a surface coil capable of observing the biochemical kinetics of $1 \mathrm{H}$ and 31P(D) were fixed to the right lower leg region. The red circle $(20 \mathrm{~mm}$ inner diameter) is the region of interest field 
Scanning for ${ }^{31} \mathrm{P}-\mathrm{MRS}$ and T2-weighted images data

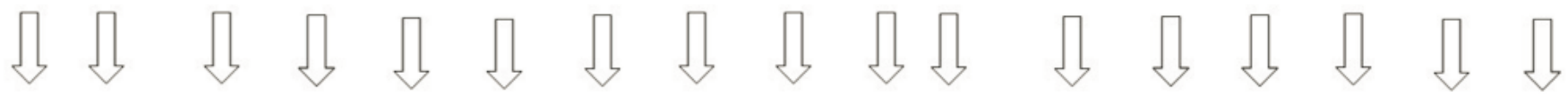

Arterial blood samples for creatine phosphokinase and $\mathrm{pH}$ concentration

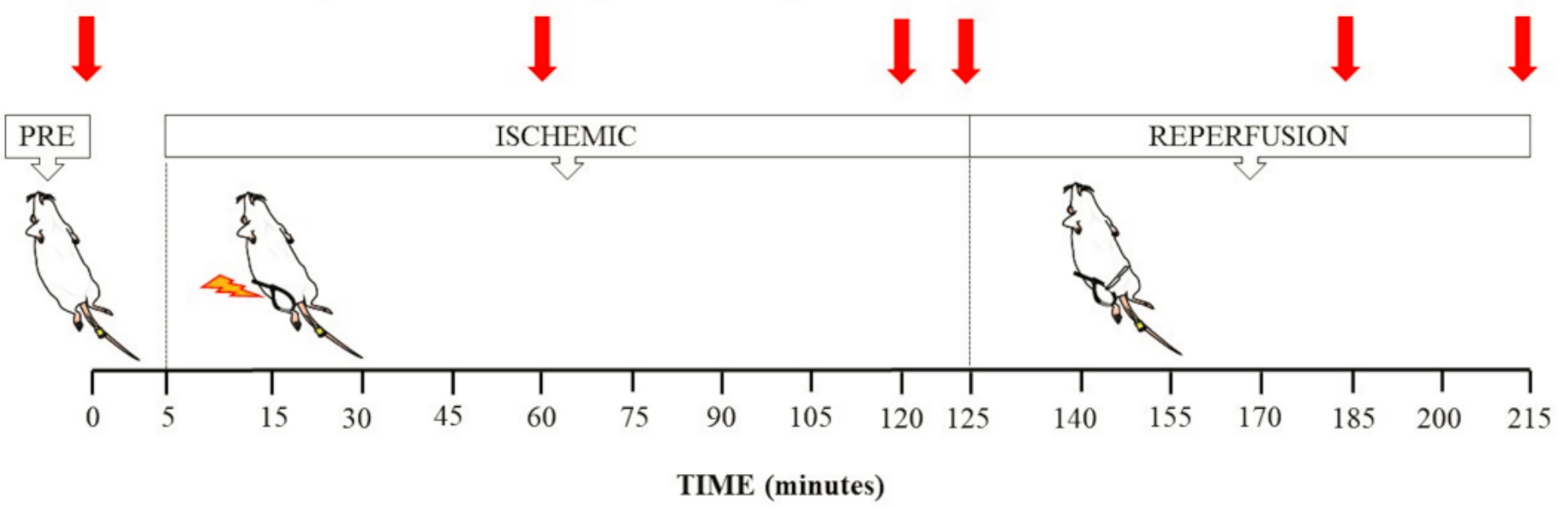

Figure 3

The experimental protocol. White arrows indicate time of collecting data for 31P-MRS and T2-weighted images. Red arrows designate time of arterial blood sampling for creatine phosphokinase and $\mathrm{pH}$ concentration.31P-MRS spectra were acquired at rest, during muscle was compressed (for 120 minutes) and reperfusion (for 90 minutes). During the MR procedure, the concentration of $\mathrm{pH}$ and $\mathrm{CPK}$ were analyzed by blood samples obtained from the tail artery.

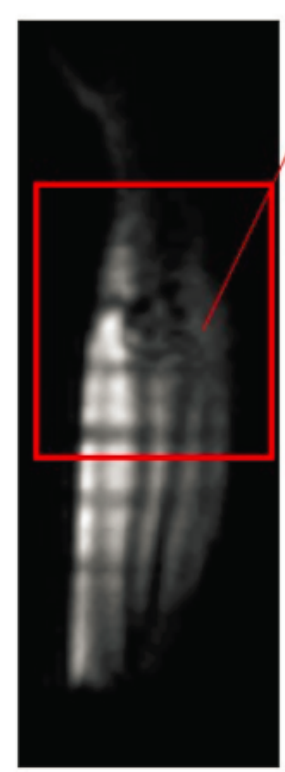

Sagittal plane
(A)

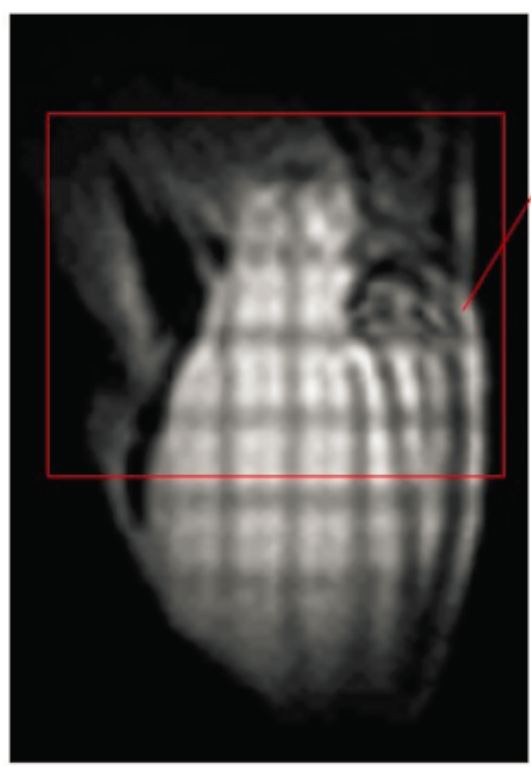

Coronal plane

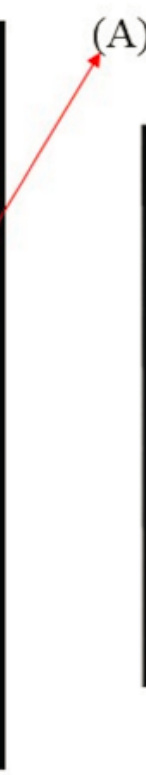

(B)

(C)

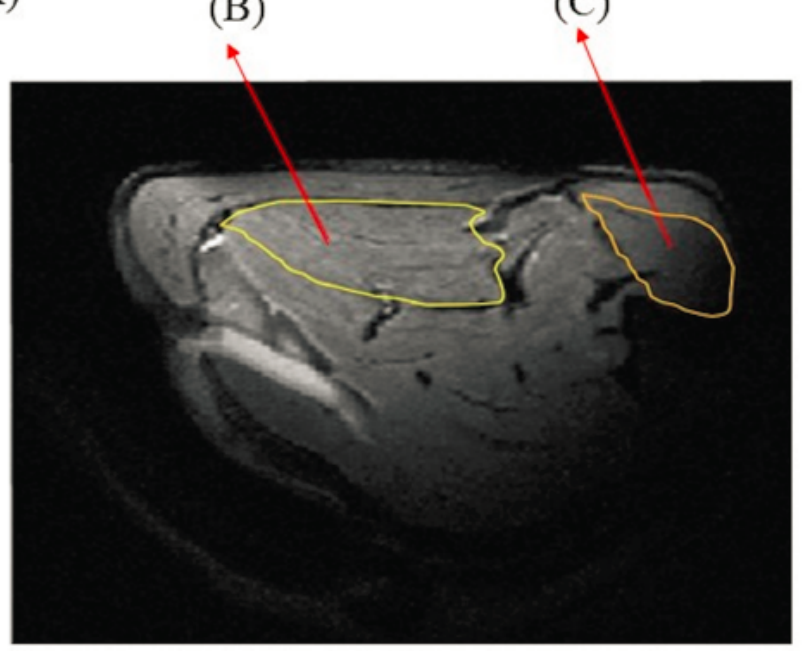

Axial slice

Figure 4 
T2-weighted images scanning plan for the detection of compartment region in rat. Red box is range of scanning's field of view. The axial slice was localized by sagittal plane and coronal plane. (A) indicates the knee joint. The locations correspond to Red gastrocnemius muscle (B) and Tibialis anterior muscle (C).

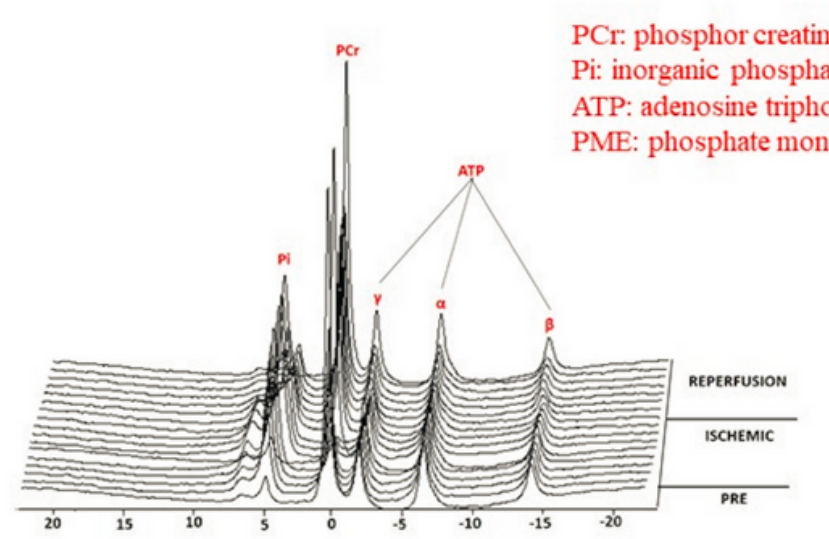

(A)

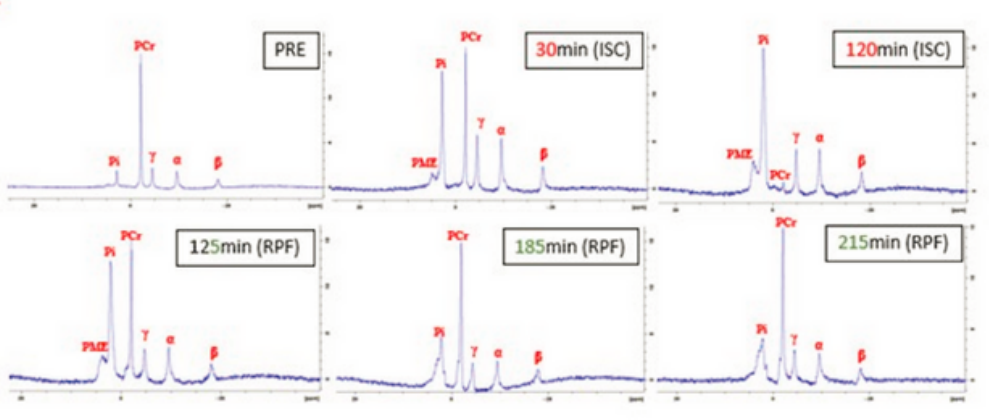

(B)

\section{Figure 5}

The dynamic graph of 31P-MRS spectrum. (A) Time series of dynamics 31P-MRS spectrum at pre, during ischemic (ISC) and reperfusion (RPF) state. (B) The change of 31P-MRS wave during the experiment. Especially, at ischemic state, phosphate monoester (PME) peak appeared at 30 minutes and gradually increased until 120 minutes of ischemic state. At the beginning of reperfusion state, PME peak started to decrease and completely disappeared at 185 minutes of reperfusion state. 
(A)

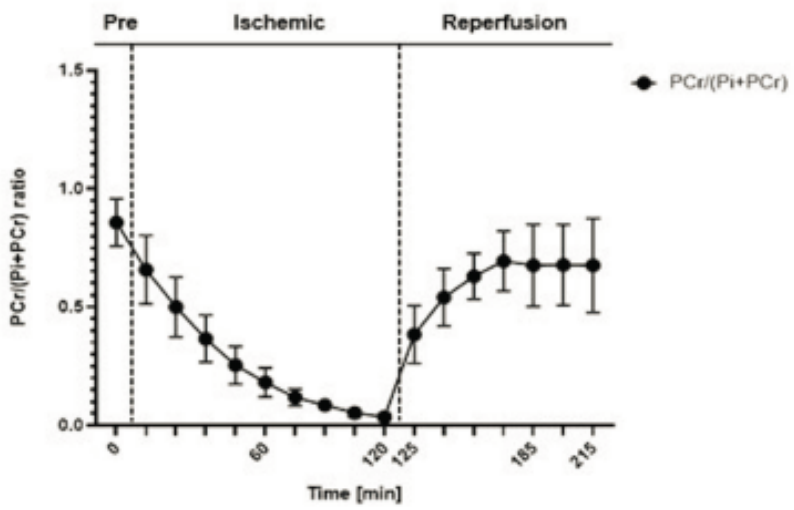

(C)

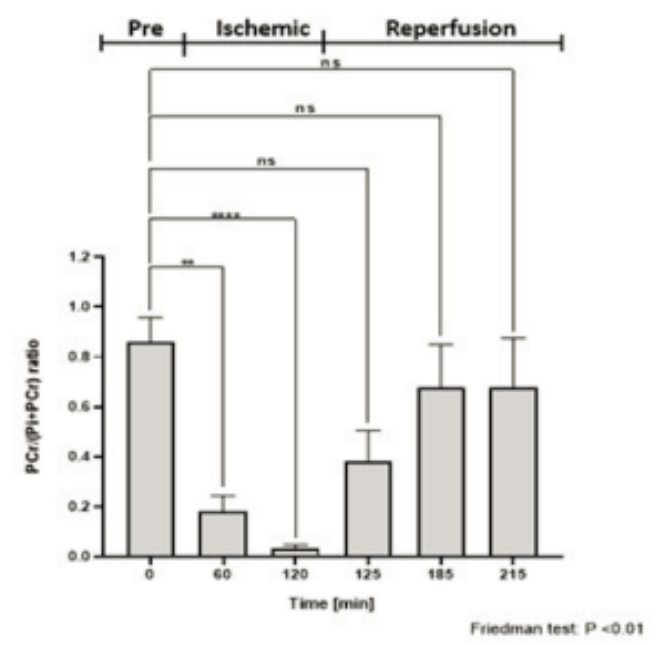

(B)

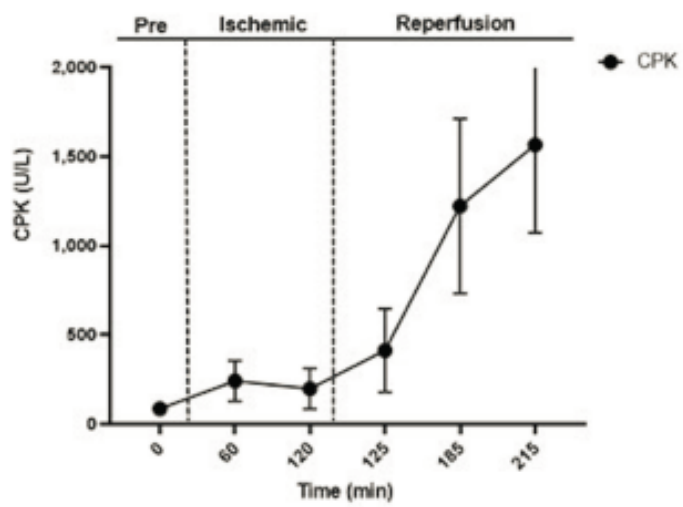

(D)

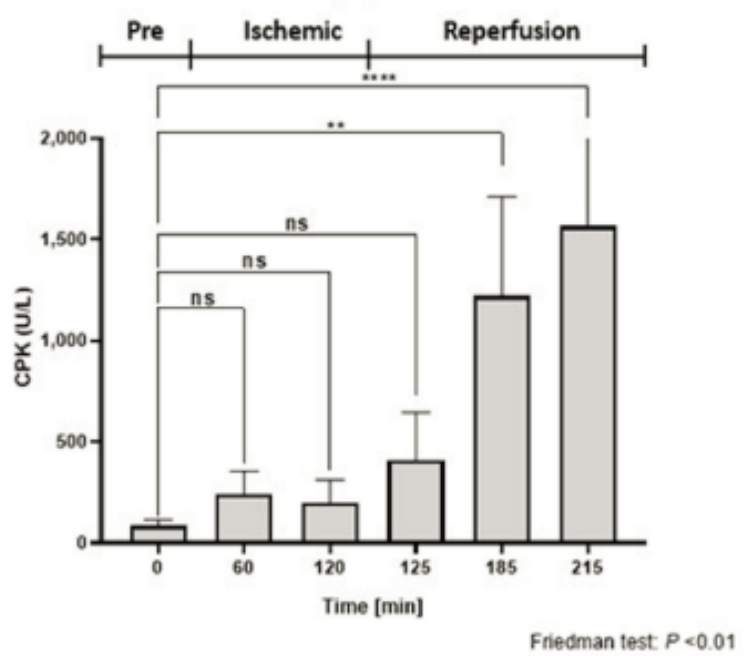

Figure 6

Dynamics in ratio of $\mathrm{PCr} /(\mathrm{Pi}+\mathrm{PCr})$ and concentration of $\mathrm{CPK}$ during ischemic and reperfusion state. (A) \& (B)Changing of $\mathrm{PCr} /(\mathrm{Pi}+\mathrm{PCr})$ ratio and $\mathrm{CPK}$ of rat skeletal muscles during 2 hours of ischemic and 1.5 hours post-ischemic. (C) \& (D) Comparison of quantitative $\mathrm{PCr} /(\mathrm{Pi}+\mathrm{PCr}$ ) ratio and CPK among 0, 60-, 120-, 125-, 185- and 215-min before, during and after ischemic. ns (not significant); ** $(0.001<P<0.005)$ and **** $(\mathrm{P}<0.0001)$ based on Friedman test. 
(A)

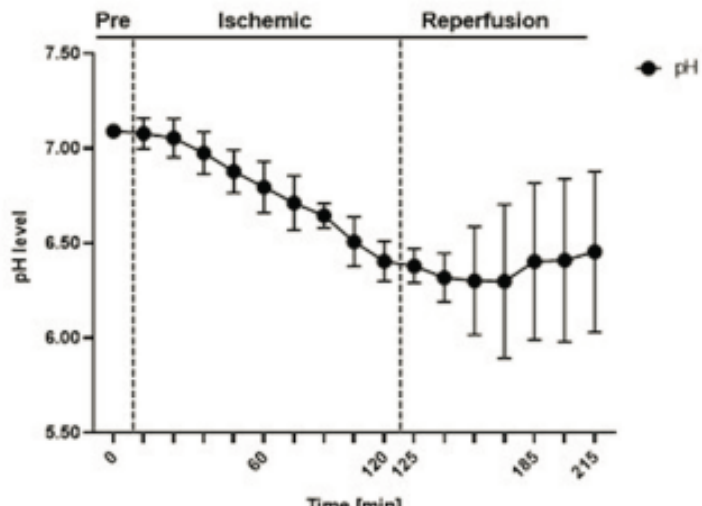

(C)

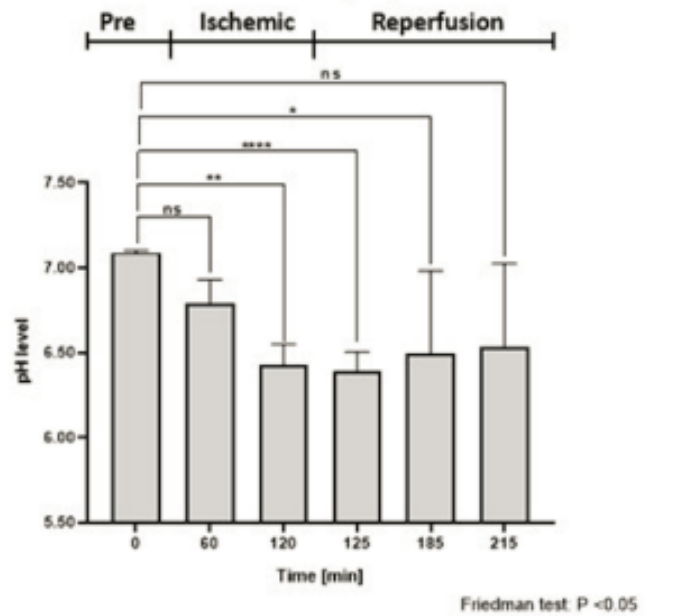

(B)

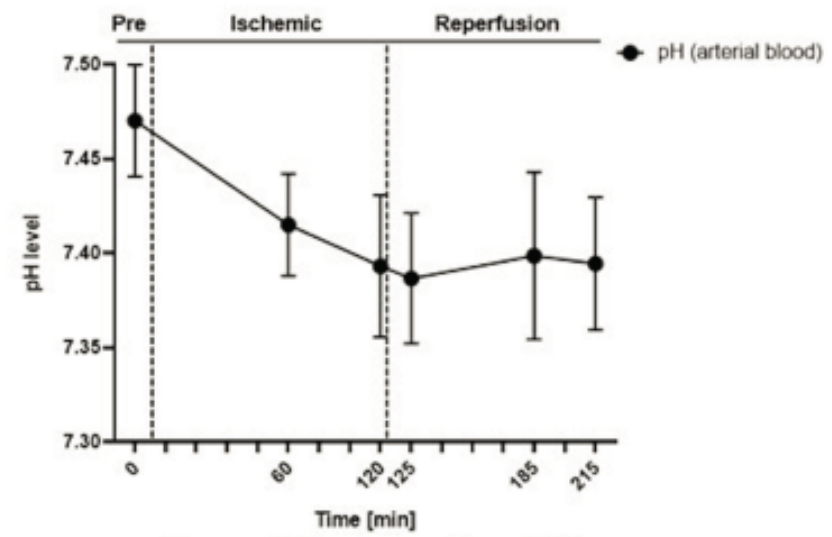

(D)

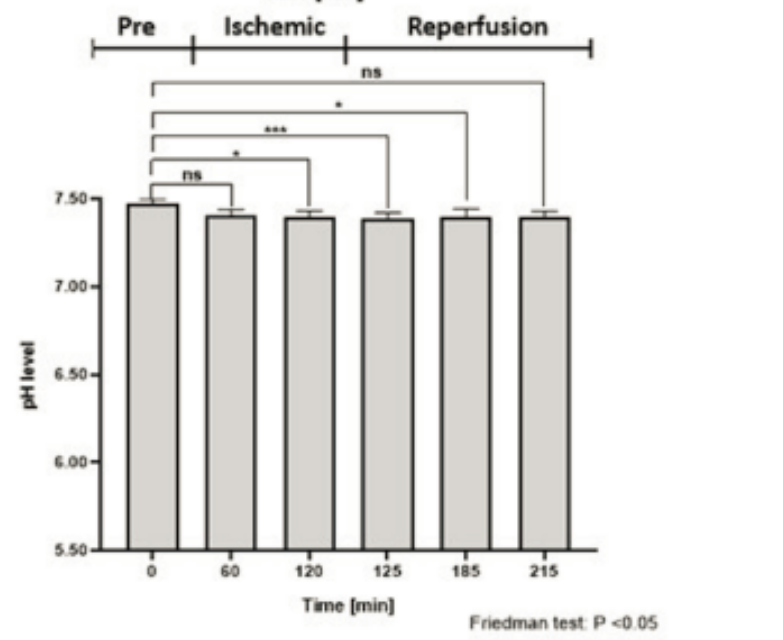

Figure 7

Dynamics in concentration of intracellular $\mathrm{pH}$ and systemic $\mathrm{pH}$ during ischemic and reperfusion state. (A) \& (B) The change of intracellular $\mathrm{pH}$ and arterial blood $\mathrm{pH}$ value during the experiment. (C) \& (D) Comparison of quantitative intracellular $\mathrm{pH}$ and arterial $\mathrm{pH}$ among pre, ischemic and reperfusion. ns (not significant); * $(0.01<P<0.05)$, ** $(0.001<P<0.005)$ and $* \star \star(P<0.001)$ based on Friedman test.
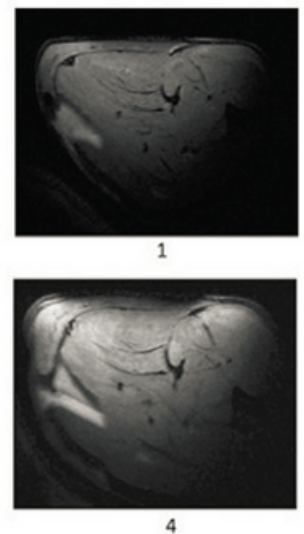
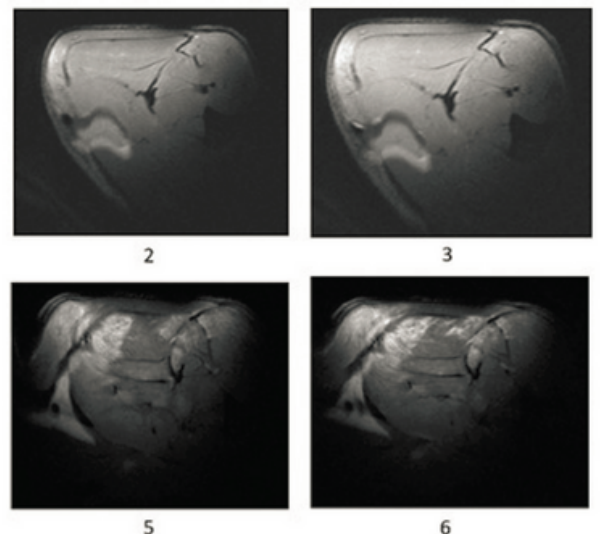

(A)

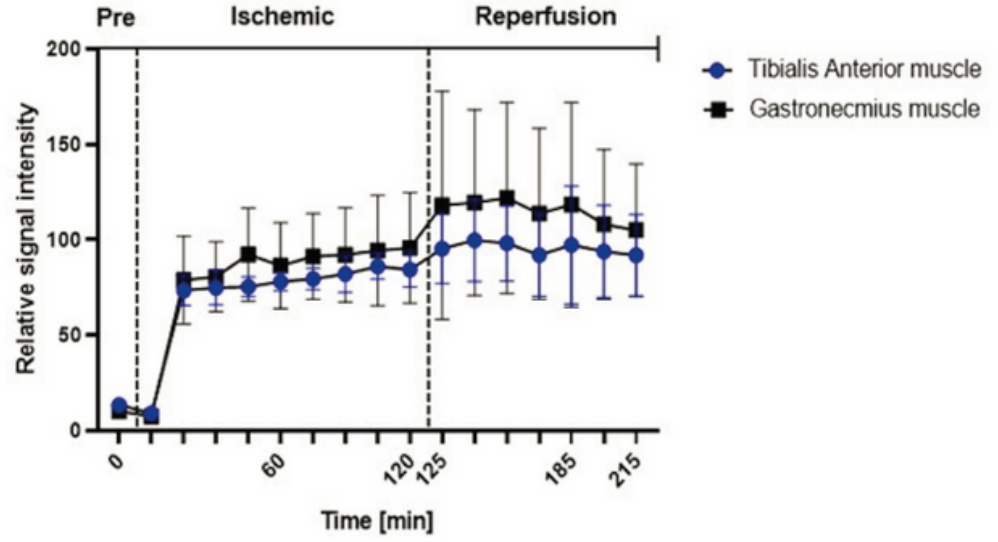

(B)

Figure 8 
The change of relative signal intensity of T2-weighted images during ischemic and reperfusion state. (A) T2-weighted images during experiment. Images at pre-ischemic (1), $60 \mathrm{~min}$ (2) and $120 \mathrm{~min}$ (3) after zipties fastened, and $5 \mathrm{~min}(4), 60 \mathrm{~min}(5)$ and $90 \mathrm{~min}(6)$ at reperfusion. (B) The mean signal intensity in T2weighted images. The mean signal intensities were calculated at two regions during the experiment (GA and TA muscles).

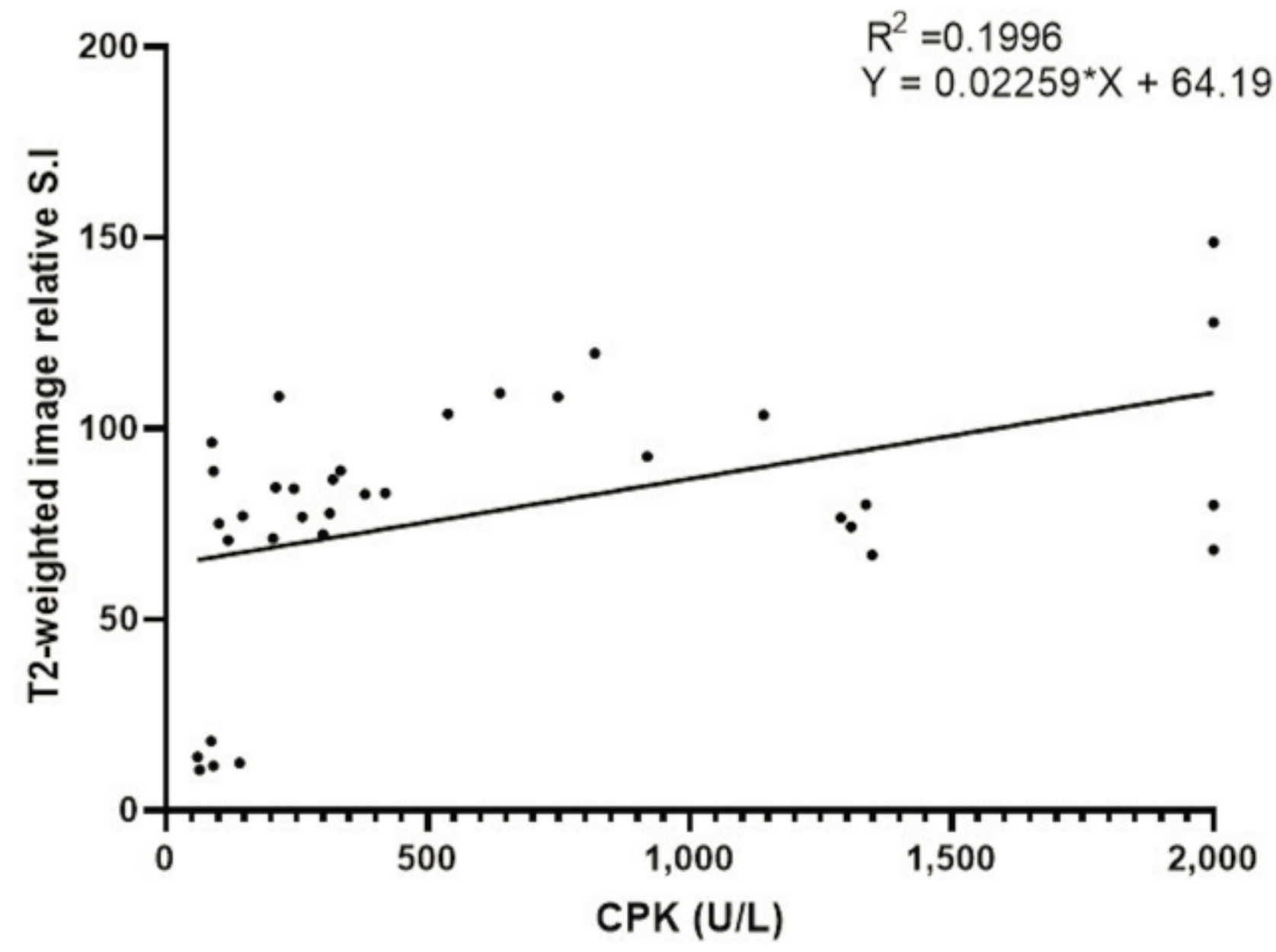

Figure 9

The correlation between T2-weighted images SI and the CPK concentration. There was a significant correlation of T2-weighted image with CPK concentration from blood examination.

\section{Supplementary Files}

This is a list of supplementary files associated with this preprint. Click to download.

- Graphicalabstract.pdf 